\title{
Empirical Modeling and Experimental Investigations on Isothermal Air-Water Two-Phase Flow through Horizontal Circular Minichannel
}

\author{
H. B. Mehta and J. Banerjee ${ }^{\dagger}$ \\ Department of Mechanical Engineering, Sardar Vallabhbhai National Institute of Technology, Surat-7, Gujarat, \\ India \\ †Corresponding Author Email: jbaner@svnit.ac.in
}

(Received September 25, 2012; accepted July 9, 2013)

\begin{abstract}
The experimentally developed flow pattern maps for micro-scale channels reported by various researchers differ significantly. Also, no theoretical models effectively predict the flow regime transition boundaries in micro-scale channel. The present work proposes an empirical model for air-water two-phase flow pattern transition boundaries for minichannel diameters between 2 to $5 \mathrm{~mm}$. Moreover, experiments are conducted with $2.5 \mathrm{~mm}$ diameter horizontal circular minichannel to develop a flow regime map. The proposed empirical model is found to provide good agreement with the experimental data. Comparisons are also shown with the work of Mandhane et al. (1974), Taitel and Dukler (1976), Barnea et al. (1983), Damianides and Westwater (1988), Coleman and Garimella (1999), Yang and Shieh (2001), Venkatesan et al. (2010).
\end{abstract}

Keywords: Empirical model, Two-phase flow, Minichannel, Flow regime map.

\section{NOMENCLATURE}

$\begin{array}{ll}\text { A,B,C } & \text { coefficients } \\ \mathrm{c}, \mathrm{c} 1 & \text { coefficients } \\ \mathrm{d} & \text { internal diameter of tube }(\mathrm{m}) \\ \mathrm{L} & \begin{array}{l}\text { length of test section from the junction } \\ (\mathrm{mm})\end{array}\end{array}$

\section{INTRODUCTION}

Gas-liquid two-phase flow in micro-scale geometries is observed in many industrial applications. Some of these applications include material processing, microchemical systems, thin film deposition technology and biotechnology systems (Shao et al., 2009), cooling of a diverter of fusion reactors and high powered electronic devices (Mishima and Hibiki, 1996), cooling of highdensity multi-chip modules in supercomputers, cryogenic cooling systems in satellites (Zhao and $\mathrm{Bi}$, 2001), high heat-flux compact heat exchangers and research nuclear reactors (Saisorn and Wongwises, 2009; Zhang et al., 2011), Pulsating Heat Pipe (PHP) cooling of an electronics thermal management (Naik et al., 2013), droplet based micro-fluidic systems (Bedram et al., 2013). For gas-liquid processes in micro-scale channels, different flow patterns are observed depending on the distribution of phases in the channel. The flow characteristics such as the pressure drop, heat and mass transfer and reaction for two-phase flow through micro-scale channels depend on these flow patterns (Cheng et al., 2008; Zhang et al., 2011). $\mathrm{m}, \mathrm{m} 1$ exponents

USG superficial gas velocity $(\mathrm{m} / \mathrm{s})$

USL superficial liquid velocity $(\mathrm{m} / \mathrm{s})$

Hence, the fundamental understanding of the two-phase flow patterns, their transition and the development of flow pattern maps in micro-scale channels is significant. According to Triplett et al. (1999), the Taylor's instability analysis, intended for the hydrodynamic interfacial process between two different phases, cannot be directly applied to micro-scale channels. This is because the diameter of micro-scale channel is approximately equal to or even smaller than the Laplace length scale. Hence, theoretical flow pattern prediction models for macroscale channels such as Taitel and Dukler (1976) and Barnea et al. (1983) fail to predict flow pattern transition lines effectively in microscale channels. The experimental studies reported in literature on gas-liquid flow in micro-scale channels and on different flow regimes are either based on simple visual inspection of flow through transparent channel or with high speed photography of flow in a channel or by measuring or quantifying the parameters like void fraction. However, there exists a significant difference in experimentally developed flow pattern maps reported by different researchers. These are due to the adoption of different terminology and also due to 
the subjectivity of two-phase flow pattern characterization.

In view of the above facts, the objective of the present study is of twofold. First, to develop an empirical model based on the experimental database available in literature for flow pattern transition boundaries in micro-sized channels. Secondly, to compare the proposed empirical model with a flow pattern map developed by carrying out experiments on a $2.5 \mathrm{~mm}$ horizontal circular minichannel. The proposed empirical model is valid for isothermal air-water twophase flow through horizontal minichannel of diameter ranging between 2 to $5 \mathrm{~mm}$. A detailed review of literature on experimental studies on air-water twophase flow through circular micro-scale channels is presented first. This is followed by a discussion on the development of the empirical model for flow regime transition boundaries. A discussion on experiments carried out on $2.5 \mathrm{~mm}$ diameter minichannel is presented next. At the end, predictions of the proposed empirical model are compared with the experimentally developed flow pattern map.

\section{LiterATURE REVIEW}

A detailed review on theoretical and experimental works reported in literature for gas-liquid flow patterns and their transitions in micro-scale channels is presented here. One of the most significant studies reported in the area of two-phase flow transitions is by Taitel and Dukler (1976). They developed an explicit semi-analytical flow regime transition model based on Kelvin-Helmholtz instability analysis applied to a stable stratified flow. This model was developed for horizontal and near horizontal gas-liquid two-phase flow through pipe. They also developed a prediction model for flow regime transition in steady gas-liquid flow through vertical tubes in 1980 (Taitel et al., 1980).But the applicability of these models for small channels was not established experimentally until 1983. Barnea et al. (1983) conducted experiments on gasliquid two-phase flow through small and medium tubes of $4,6,8.15,9.85$ and $12.3 \mathrm{~mm}$ diameter for horizontal and upward flow configuration. Based on the disagreement of their experimental results with Taitel and Dukler (1976) and Taitel et al. (1980) for stratified to slug flow transition, they proposed that the transition in micro-scale channels would not be governed by Kelvin-Helmholtz instability. They proposed new model by considering the effect of surface tension which is dominant in micro-scales.

The models proposed by Taitel and Dukler (1976) as well as Barnea et al. (1983) however failed to predict the flow transitions accurately for micro-scale channels. The effect of tube diameters on the stratified regime was experimentally studied by Damianides and Westwater (1988) by considering horizontal circular tube of 1 to 5mmdiameter. During their experiments, they observed (1) intermittent to dispersed flow transition in larger tubes at larger liquid flow with increase in liquid flow; (2) intermittent to annular transition in smaller tube sat larger gas flow with increase in gas flow; (3) decrease in stratified flow regime with decrease in tube size and complete elimination of stratified regime for the tube of $1 \mathrm{~mm}$ diameter. In order to decide the critical pipe diameter for which surface tension forces become predominant over gravitational forces, Fukano and Kariyasaki (1993) conducted experiments on tubes with diameter from 1 to $9 \mathrm{~mm}$. They did not find separated flow in capillary tubes and predicted the critical pipe diameter between 5 to $9 \mathrm{~mm}$. The experimental development of flow regime maps for gas-liquid flow through small diameter tube was also reported by Barajas and Panton (1993), Mishima et al. (1993) and Mishima and Hibiki (1996). They performed their experiments with similar hydraulic internal diameter tube as was considered by Fukano and Kariyaski (1993). They did not observe stratified flow in small diameter pipes and found qualitative agreement between their developed flow pattern maps. The effect of channel size and shape on gas-liquid flow transition in micro-scale channels was reported by Coleman and Garimella (1999). They considered circular and non-circular capillaries with diameters of 1.3, 1.75, 2.6 and $5.5 \mathrm{~mm}$. They compared the observed transition boundaries with the transition model of Taitel and Dukler (1976) and found poor agreement for small diameters. Hence, they concluded the significance of aspect ratio, hydraulic diameter and surface tension to locate flow regime transitions in micro-scale channels. Triplett et al. (1999) experimentally developed gas-liquid two-phase flow pattern maps for circular micro-channel of 1.1 and $1.45 \mathrm{~mm}$ internal diameter and for non-circular microchannels of 1.09 and $1.49 \mathrm{~mm}$ hydraulic diameters. Their results were found to be consistent with the observation of Damianides and Westwater (1988) and Fukano and Kariyaski (1993). They too observed the significance of surface tension in capillaries and did not find any effect of channel orientation on the flow characteristic.

The surface tension forces in micro-scale channels were further investigated by Yang and Shieh (2001). They performed experiments for air-water and the refrigerant $\mathrm{R}-134 \mathrm{a}$, which has much lower surface tension as compared to air-water, with circular tube of 1 to $3 \mathrm{~mm}$ diameter in horizontal orientation. They found poor agreement with the prediction model of Taitel and Dukler (1976) and significant effect of fluid properties on flow regimes and flow pattern maps. Chen et al. (2002) conducted experiments on circular glass tube of 1 and $1.5 \mathrm{~mm}$ diameter in horizontal and vertical configuration using nitrogen-water and observed bubbly, Taylor (slug and bubble train slug), churn and annular flow regimes. They presented bubble rise velocity correlation and modified drift flux model for void fraction prediction. A considerable scatter was found in two-phase flow regime maps and semianalytical transition models reported in literature. In order to systematically compare and assess the available experimental data for two-phase flow through microscale channel, Akbar et al. (2003) conducted experiments on gas liquid two-phase flow regimes in micro-channels. They presented flow regime maps for hydraulic diameter closer to $1 \mathrm{~mm}$ by classifying into three zones namely surface tension dominated zone, inertia dominated zone and transition zone.

The definition of micro-scale channel was an important aspect of two-phase flow studies prior to 2003 . Kandlikar and Grande (2003) defined micro-scale 
channel considering the rarefaction effect of common gases at atmospheric pressure. According to them, the threshold limit between conventional channel and minichannel was $3 \mathrm{~mm}$, between minichannel and micro-channel as $0.2 \mathrm{~mm}$ and between micro-channel and nano-channel as $0.001 \mathrm{~mm}$. The effect of influencing parameters on two-phase flow through micro-channel was studied and reviewed by various researchers and they all found the predominance of surface tension over buoyancy force (Chung and Kawaji, 2004), Vaillancourt et al., 2004, Zobeiri, 2006, Pehlivan et al., 2006, Pohorecki et al., 2008, Saisorn and Wongwises, 2008, 2009, 2010), Shao et al., 2009).

Recently, the effect of tube diameter on two-phase flow pattern maps and pressure drop was experimentally studied by Venkatesan et al. (2010). They considered different tubes of diameters0.6, 1.2, 1.7, 2.6 and 3.4 $\mathrm{mm}$ and proposed new frictional pressure drop correlation based on channel diameter for different flow regimes. The effect of channel size and fluid properties such as surface tension and viscosity was studied by Zhang et al. (2011). They studied two-phase flow through micro-channel of 302, 796 and $916 \mu \mathrm{m}$ diameter. Their results were in agreement with the flow pattern maps presented by Triplett et al. (1999) and Hassan et al. (2005) but were in poor agreement with the maps of Yang and Shieh (2001). They proposed new transition criterion considering the effect of channel size and fluid properties. Most recently, Abiev and Lavretsov (2012) made experiments on horizontal capillaries with inner diameters of $0.92,1.70,1.86$ and $2.53 \mathrm{~mm}$ in order to understand hydrodynamics and mass transfer of slug flow with the mixture of air-water and air-glycerol. They proposed new correlations for bubble rise velocity, semi-empirical formula for Sherwood number in a wide range of capillary number and pressure drop calculation method in minichannel. Leung et al. (2012) experimentally studied the gravitational effect on Taylor flow in horizontal circular micro-channels of internal diameters 1.12, 1.69 and $2.12 \mathrm{~mm}$. They used Micro-Particle Image Velocimetry $(\mu \mathrm{PIV})$ measurements on liquid film thickness.

Based on the above literature, the following issues can be summarized:

1. The threshold diameter between micro, mini and macro channel are still to be defined.

2. Theoretical flow pattern transition models are not developed for micro-scale channels.

3. In micro-scale channels, the gravity effect is greatly suppressed by the surface tension effect with decrease in diameter. Hence, two-phase flow patterns in micro-scale channel have different behavior as compared to macroscale channels. A large dataset on the effect of surface tension is required to effectively predict the stratified to other flow regime in minichannel in the range of 2 to 5 mm diameter.

4. For the same fluid and test conditions adopted by different researchers, flow pattern observations and subsequently developed flow pattern transition maps in minichannel are inconsistent. Systematic and well-designed experiments are needed to understand the fundamentals of gas-liquid transport mechanisms.

Flow transition boundaries greatly depend on channel size, operating conditions and fluid properties. It is thus required to establish correlations to establish the influence of these parameters on flow pattern transitions.

The aim of the present study is to develop an empirical model for air-water two-phase flow transition in minichannel diameter ranging between 2 to $5 \mathrm{~mm}$ and to systematically compare the minichannel based flow pattern maps existing in the literature with the developed empirical model. An experimental investigation is carried out for establishing flow patterns through a $2.5 \mathrm{~mm}$ diameter horizontal circular channel. The proposed correlation is also compared with the flow pattern map developed with these experimental results.

\section{DEVELOPMENT OF AN EMPIRICAL MODEL}

A discussion on the development of an empirical correlation for flow pattern transition boundaries is presented in this section. The transition boundaries are shown on the flow pattern map with superficial velocities of liquid and gas phases (USG and USL) as the coordinates. Four flow regimes considered here are intermittent flow, stratified flow, dispersed flow and annular flow. Thus, there exist three transition lines. They are intermittent to annular, intermittent to dispersed and stratified to other flows. For the development of an empirical model, the transition lines are considered to be functions of operating conditions (USG and USL) and channel diameter. The systematic development procedure for each transition line is presented as follows:

\subsection{Intermittent to Annular Transition Line}

Figure 1 shows the effect of channel diameter on the intermittent-annular transition boundary. These transition lines are drawn based on an interpolation of the experimental results presented by Damianides and Westwater (1988), Fukano et al. (1989), Triplet et al. (1999), Coleman and Garimella (1999), Yang and Shieh (2001), Chen et al. (2004), Vaillancourt et al. (2004) and Zobeiri (2006). It is to be noted here that the intermittent regime shrinks with the increase of tube diameters from 1 to $5 \mathrm{~mm}$ and with decrease in gas velocity. The effect is lesser in the range of 1 to $2 \mathrm{~mm}$ tube diameter.

The functional relationship between UGS and ULS is assumed to follow the form given by Eq. (1).

$U_{S L}=c U_{S G}^{m}$

where coefficient(c) and exponent (m) are evaluated using method of least square on the data set shown in Fig. 1. Different values of $\mathrm{c}$ and $\mathrm{m}$ are observed for different diameters. The variation of $\mathrm{c}$ and $\mathrm{m}$ are drawn as a function of diameter (d) in Fig.2.

The functional relationship derived in terms of $\mathrm{c}_{1}$ and $\mathrm{m}_{1}$ is shown in Eq. (2). 
H. B. Mehta and J. Banerjee / JAFM, Vol. 7, No. 2, pp. 227-237, 2014.

$U_{S L}=(c 1) U_{S G}^{(m 1)}$

Here, $c_{1}$ is found to follow polynomial relation given in Eq. (3) while exponent $\left(\mathrm{m}_{1}\right)$ is found to follow the Boltzmann relation given in Eq. (4).

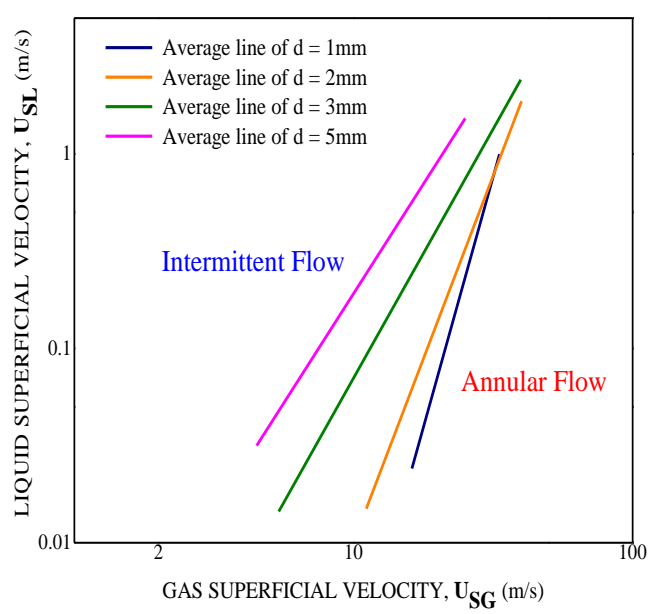

Fig. 1. Intermittent to annular averaged transition boundary based on the experimental data available in literature
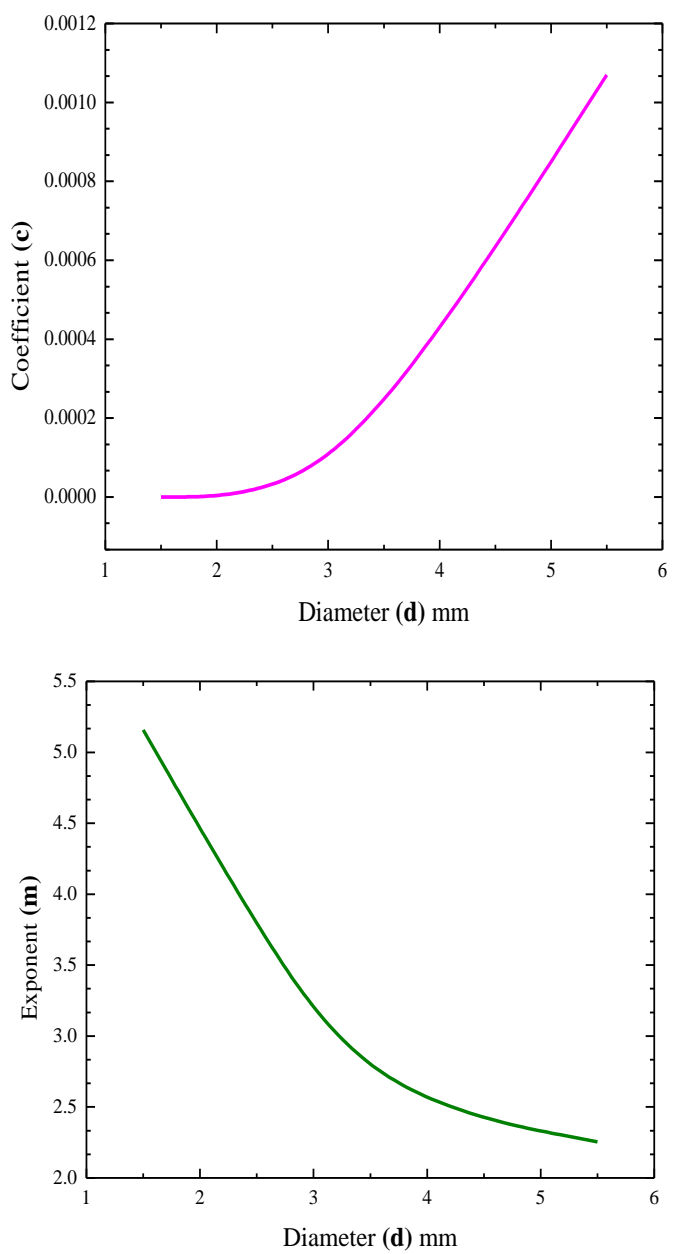

Fig. 2. Co-efficient $(c)$ and exponent $(m)$ as a function of diameter $(d)$

$$
c 1=\left(\begin{array}{l}
6.3727-7.5686 d+2.5345 d^{2} \\
-0.1696 d^{3}
\end{array}\right) \times 10^{(-4)}
$$

$$
m 1=\frac{3.98568}{1+e^{\left(\frac{d-1.69033}{0.67317}\right)}}+2.22447
$$

Substituting $c_{1}$ and $m_{1}$ from Eq. (3) and Eq. (4) into Eq. (2), the relationship between UGS and ULS is obtained as

$$
\begin{aligned}
& U_{S L}=\left(\begin{array}{l}
6.3727-7.5686 d+2.5345 d^{2} \\
-0.1696 d^{3}
\end{array}\right) \times 10^{(-4)}
\end{aligned}
$$

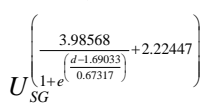

Equation (5) is an empirical equation for transition between intermittent and annular flow for minichannel. This equation is valid for minichannel diameters in the range of 2 to $5 \mathrm{~mm}$.

\subsection{Intermittent to Dispersed Transition Line}

The effect of tube diameter on the intermittentdispersed transition line is shown in Fig. 3. These transition lines are plotted based on an interpolation of the experimental results of Damianides and Westwater (1988), Yang and Shieh (2001) and Venkatesan et al. (2010). It is worth to be noted here that the intermittent regime expands with the increase in tube diameters from 1 to $5 \mathrm{~mm}$ and with increase in liquid velocity. The effect is observed lesser in the range of 1 to $3 \mathrm{~mm}$ tube diameter. From the above dataset, Eq. (6) is developed to predict the intermittent to dispersed transition lines. This transition line is valid for minichannel diameters in the range of 1 to $5 \mathrm{~mm}$.

$U_{S L}=0.6119-0.0871 d+0.04545 d^{2}$

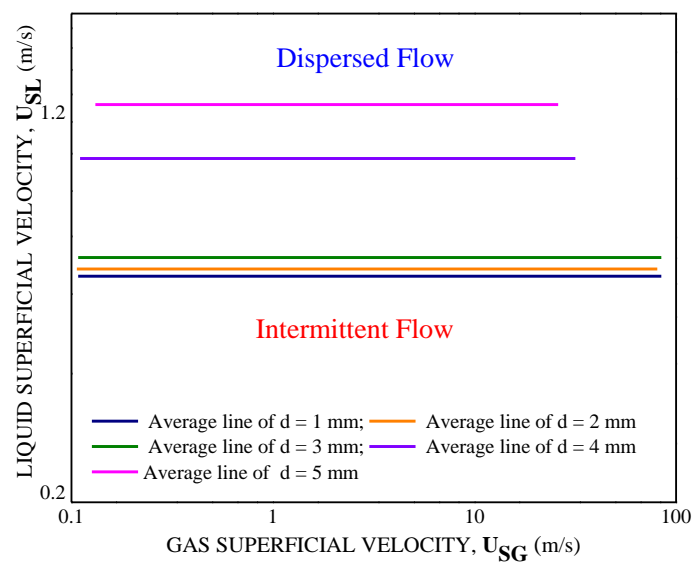

Fig. 3. Intermittent to dispersed averaged transition boundary based on the experimental data available in literature 


\subsection{Stratified to other Flow Transition Line}

The effect of tube diameter on transition from stratified to other flow is shown in Fig.4. These transition lines are plotted based on an interpolation of the experimental results of Damianides and Westwater (1988), Coleman and Garimella (1999), Yang and Shieh (2001) and Venkatesan et al. (2010). Stratified flow is not observed for pipes below $2 \mathrm{~mm}$ diameter and the regime expands with the increase of tube diameters from 2 to $5 \mathrm{~mm}$ with increase in liquid velocity. From the above dataset, Eq. (7) is developed for transition line between stratified to other flow pattern lines. This line is valid for minichannel diameters in the range of 2 to $5 \mathrm{~mm}$.

$U_{S L}=A+B U_{S G}+C U_{S G}^{2}$

where the coefficients are given by the following relations

$A=-0.0125+0.0014 d ; B=-0.00124+0.0021 d ;$

$C=(1.5598-1.0199 d) \times 10^{-4}$

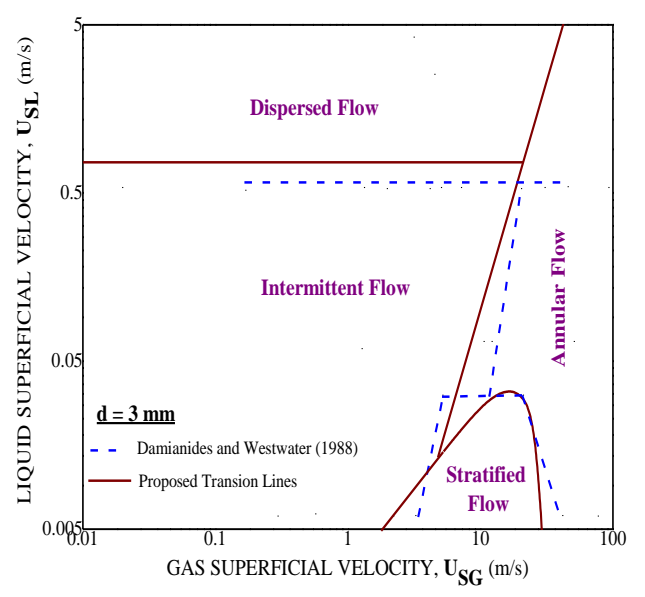

(a) Damianides and Westwater (1988)

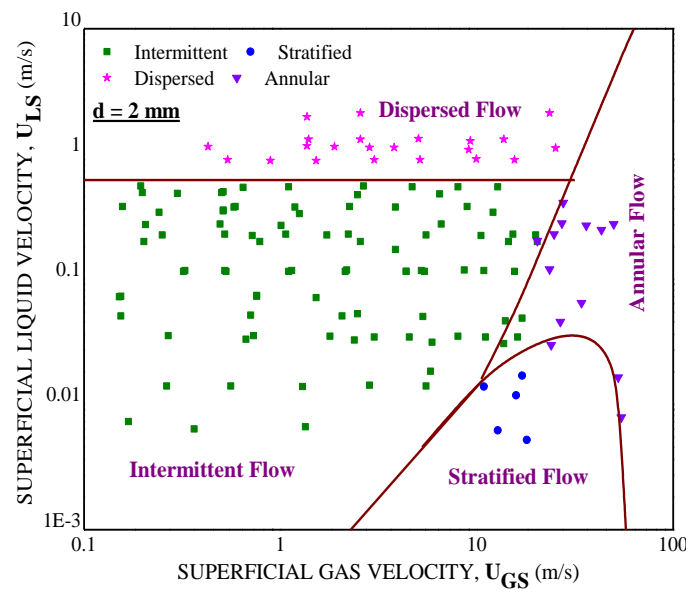

(C) Yang and Shieh (2001)

\section{COMPARISON OF AN EMPIRICAL MODEL WITH LITERATURE}

In order to check the predictability of the developed model, a comparison of the empirically developed flow pattern transition boundaries with the available experimental database in literature for air-water twophase flow is shown in Fig. 5.

The flow regime map is shown for intermittent flow, dispersed flow, annular flow and stratified flow. The prediction of intermittent-dispersed and intermittentannular transition is found to be in good agreement with available literature for different range of minichannel diameters. The fact that the stratified flow is rarely observed for micro-scale channels is also represented by this developed empirical model. As shown in Fig. 5, the prediction of stratified to other flow transition is found to be in good accord with the dataset of Damianides and Westwater (1988) as well as Yang and Shieh (2001), while it is found to agree reasonably well with other researchers.

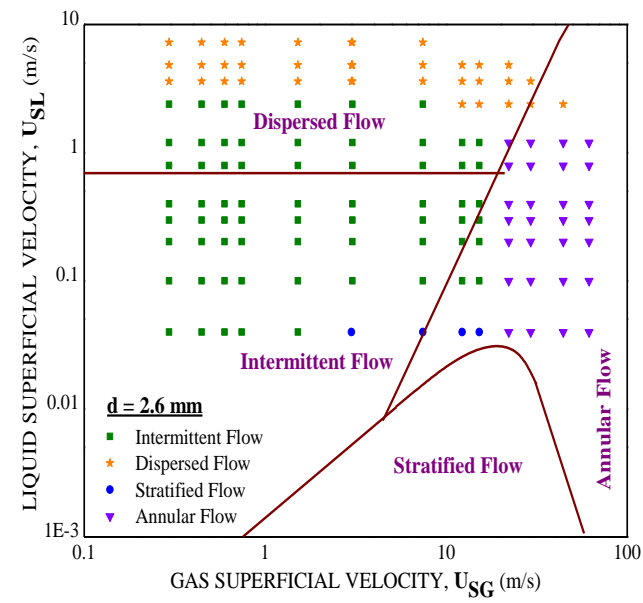

(b) Coleman and Garimella (1999)

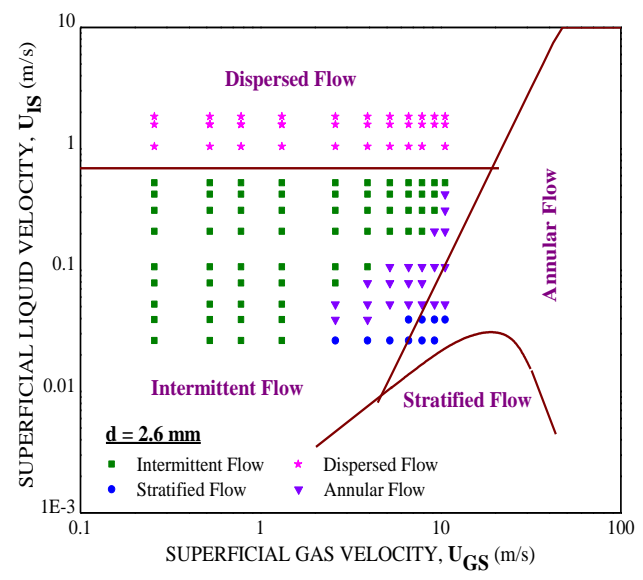

(d) Venkatesan et al. (2010)

Fig. 5. Comparison of the proposed transition boundary (lines) and the experimental data from the literature (symbols) 


\section{EXPERIMENTAL STUDY}

Although A schematic diagram of the flow visualization setup developed for isothermal investigation of airwater two-phase flow through minichannel is shown in Fig.6.

The setup consists of an acrylic sheet of $8 \mathrm{~mm}$ thickness pivoted centrally with collar bush. This allows the test setup to be rotated to any angle (up to $360^{\circ}$ ) in order to facilitate investigation of the effect of flow orientation on two-phase flow regimes, flow pattern maps, pressure drop and void fraction. The test section is a straight circular mini pipe fixed on the acrylic sheet. There is provision to change the diameter of the pipe and inlet configurations. The results reported here are for experiments carried out for $2.5 \mathrm{~mm}$ diameter pipe. A variety of flow patterns are visualized by controlling the flow rates of air and water. Flow patterns are observed at sufficient distance $(\mathrm{L} / \mathrm{d}=250)$ from the inlet section to minimize the influence of entrance region.

The fluids used are air and water. The density and dynamic viscosity at room temperature $\left(25^{\circ} \mathrm{C}\right)$ are 1.185 $\mathrm{kg} / \mathrm{m}^{3}$ and $1.8484 \times 10^{-5} \mathrm{~Pa}-\mathrm{s}$ for air while $997.1 \mathrm{~kg} / \mathrm{m}^{3}$ and $8.936 \times 10^{-4} \mathrm{~Pa}$-s for water respectively. The surface tension for water with air is found as $0.07199 \mathrm{~N} / \mathrm{m}$. Water is stored in a $0.5 \mathrm{~m}^{3}$ capacity nonporous light weighted cylindrical polyethylene tank. Water is pumped through a $0.3729 \mathrm{~kW}$ capacity of pump. The water pressure is regulated with the help of a regulator and a bypass system to $0.2 \mathrm{MPa}$. Three different rotameters with flow measuring ranges $1.6667 \times 10^{-7}$ to $8.3333 \times 10^{-6} \mathrm{~m}^{3} / \mathrm{s}, \quad 3.3333 \times 10^{-6}$ to $3.3333 \times 10^{-5} \mathrm{~m}^{3} / \mathrm{s}$ and $6.6667 \times 10^{-6}$ to $8.3333 \times 10^{-5} \mathrm{~m}^{3} / \mathrm{s}$ are connected to the inlet section for precise measurement of water flow rates. The accuracy of the rotameters at $0.2 \mathrm{MPa}$ is \pm $2 \%$ of its full scale reading. Water is then passed through a flexible PU pipe to the inlet of the test section. A non Return Valve is located at the exit of rotameters. Air is supplied to the test section using an air compressor. Air pressure is regulated to $0.2 \mathrm{MPa}$ with a pressure regulator. It is subsequently passed through four different rotameters with flow measuring ranges of $6.6667 \times 10^{-7}$ to $8.3333 \times 10^{-6} \mathrm{~m}^{3} / \mathrm{s}, \quad 0$ to $8.3333 \times 10^{-5} \mathrm{~m}^{3} / \mathrm{s}, \quad 1.6667 \times 10^{-5}$ to $3.3333 \times 10^{-4} \mathrm{~m}^{3} / \mathrm{s}$ and $6.6667 \times 10^{-5}$ to $8.3333 \times 10^{-4} \mathrm{~m}^{3} / \mathrm{s}$. Air and water enter into the test section through different inlet geometries and are returned to the reservoir where they are separated and recycled. The flow patterns are observed with the help of image recording system. It consists of light source, high speed camera, tripod stand, memory card and computer. The camera has the capability of capturing video movies at the rates between 30 to 1000 frames per second (fps). Data from memory card is then transferred to the Personal Computer for post processing.

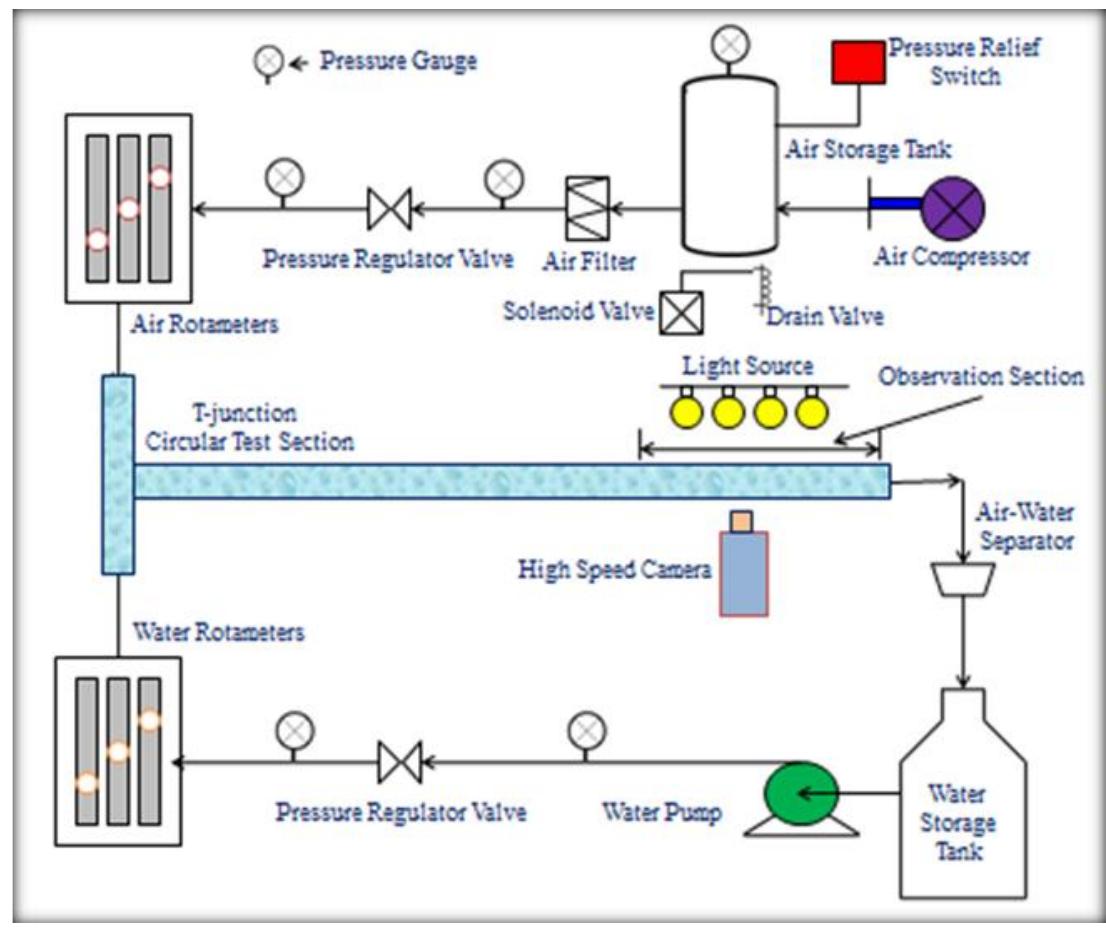

Fig. 6. Schematic diagram of the experimental setup

\section{RESULTS AND DISCUSSION}

\subsection{Flow Pattern}

Various flow patterns are visually observed for airwater two-phase flow through horizontal circular channel of $2.5 \mathrm{~mm}$ internal diameter. The superficial velocities are varied in the range of 0.0326 to 1.6317 $\mathrm{m} / \mathrm{s}$ for water and 0.1305 to $16.3173 \mathrm{~m} / \mathrm{s}$ for air. The corresponding Reynolds number range for water is 21.34 to 2667 while for air is 92.86 to 4643. The uncertainty analysis was carried out using Kline \& McClintock method (Kline et al. 1953). The calculation shows the uncertainty of $4.4623 \%$ for flow velocities and $3.922 \%$ for Reynolds number. Six different flow patterns, slug, bubbly, slug-bubbly, slug-annular, 
annular and churn flow, are observed. The observation is carried out by keeping air flow rate constant and varying the water flow rate. For each observation, the experiment took about 10-15 minutes for the stabilization of two-phase flow and good reproducibility was observed under steady state condition for each flow regime. Here, the mixture of air-water flow enters from right in all the pictures shown in Fig. 7.

Figure 7(a) shows Slug flow regime (Taylor slug regime). It is defined as elongated gas bubble having axial length more than the channel diameter and occupies nearly entire cross-section area of the channel. Liquid is plugged between consecutive gas slugs and separates the gas slugs in a channel. The gas bubble length decreases and liquid slug length increases with decrease in gas flow rate. Slug-Annular flow regime is shown in Fig. 7(b). When gas flow rate is increased in slug flow regime at reasonably lower liquid flow rate, gas bubbles try to merge with each other. With increase in liquid flow rate, slug becomes smaller and move together. As shown in Fig. 7(c), Bubbly flow regime is defined as the distinct spherical or non-spherical bubbles with diameter less than the channel internal diameter. When liquid flow rate is increased in the lower range of gas flow rate, this regime is observed. The increase in liquid velocity promotes the liquid drag forces which speed up detachment process of gas bubbles at the inlet of the channel. Gas bubbles smaller than the channel diameter is observed to move near upper wall of the channel which shows the effect of buoyancy. Slug-Bubbly flow is characterized by long and sort gas bubbles generated when gas flow rate is increased in the bubbly flow range as shown in Fig. $7(d)$. At moderate gas flow rate with high liquid flow rate, Churn flow is observed and shown in Fig. 7(e). The long Taylor bubble becomes unstable at its trailing end which leads to distraction and entrainment of gas into the liquid. Churn flow is very chaotic having irregular gas-liquid interface. Annular flow pattern is observed when gas flow rate is further increased in slug-annular flow regime. In this regime, gas flows as main core while liquid flows around the core as shown in Fig. 7(f).

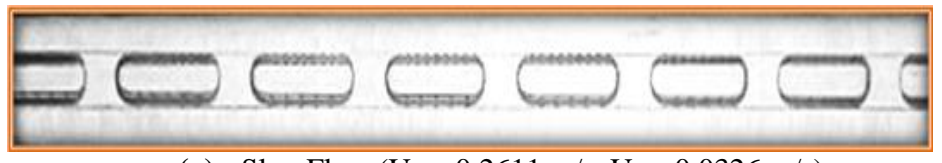

(a) Slug Flow $\left(\mathrm{U}_{\mathrm{SG}}=0.2611 \mathrm{~m} / \mathrm{s}, \mathrm{U}_{\mathrm{SL}}=0.0326 \mathrm{~m} / \mathrm{s}\right)$

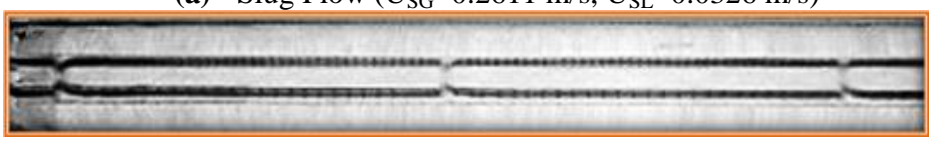

(b) Slug-Annular Flow $\left(\mathrm{U}_{\mathrm{SG}}=1.3054 \mathrm{~m} / \mathrm{s}, \mathrm{U}_{\mathrm{SL}}=0.0979 \mathrm{~m} / \mathrm{s}\right)$

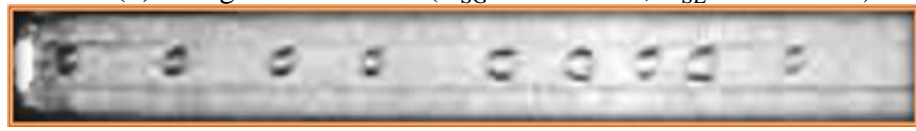

(c) Bubbly Flow $\left(\mathrm{U}_{\mathrm{SG}}=0.1305 \mathrm{~m} / \mathrm{s}, \mathrm{U}_{\mathrm{SL}}=0.9790 \mathrm{~m} / \mathrm{s}\right)$

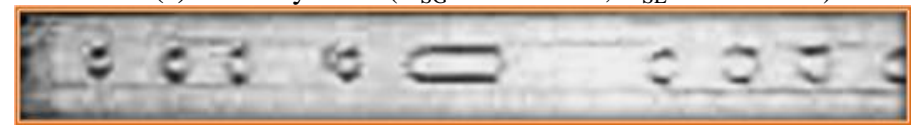

(d) Slug-Bubbly Flow $\left(\mathrm{U}_{\mathrm{SG}}=0.6527 \mathrm{~m} / \mathrm{s}, \mathrm{U}_{\mathrm{SL}}=0.6527 \mathrm{~m} / \mathrm{s}\right)$

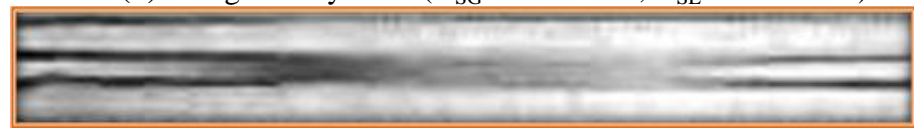

(e) Churn Flow $\left(\mathrm{U}_{\mathrm{SG}}=6.5269 \mathrm{~m} / \mathrm{s}, \mathrm{U}_{\mathrm{SL}}=0.6527 \mathrm{~m} / \mathrm{s}\right)$

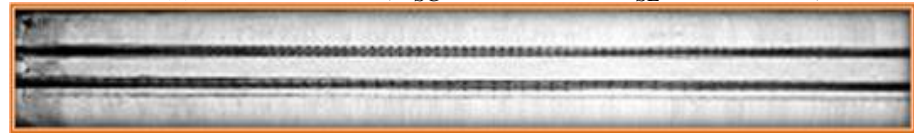

(f) Annular Flow $\left(\mathrm{U}_{\mathrm{SG}}=16.3173 \mathrm{~m} / \mathrm{s}, \mathrm{U}_{\mathrm{SL}}=0.0326 \mathrm{~m} / \mathrm{s}\right)$

Fig. 7.

\subsection{Flow Pattern Map}

The visualized flow pattern data are plotted as shown in Fig.8 (a) with gas and liquid superficial velocities as coordinates. Different flow regime transition lines are identified and traced on the map as shown in Fig.8 (b). At low air and water velocities, slug flow is observed. Slug flow changes to annular flow with increase in air velocity. Bubbly flow and churn flow are observed at high water flow conditions. It is found that major area of the flow pattern map is occupied by the slug and bubbly flow regime. This is known as surface tension dominated regime. The transition from slug flow to annular flow is not sharp. Within certain air velocity range, slug flow and annular flow dominate alternatively in the test section and hence this region is termed as slug-annular flow on the flow pattern map. This region shows that inertia forces try to become dominant but surface tension or interfacial forces are still strong in this region. At higher air flow velocities, inertia forces become very strong over interfacial forces and hence annular flow is observed. 


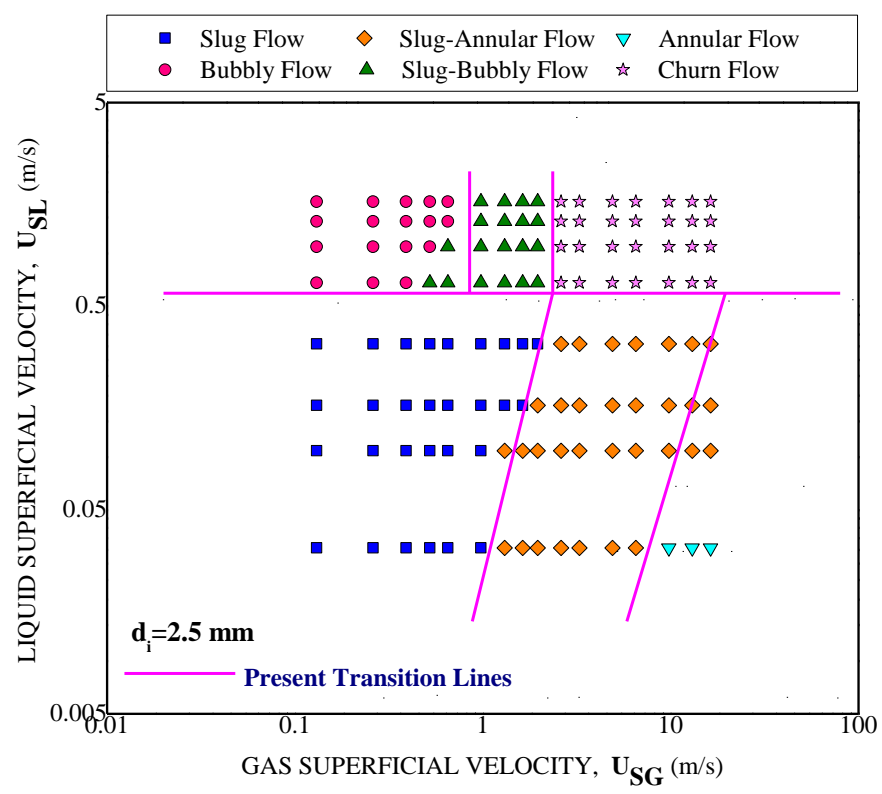

Fig. 8. Experimentally Observed Flow patterns and transition lines

\subsection{Comparison with Existing Flow Regime Maps}

The flow regime map developed based on the experimental study is compared with the maps cited in literature by researchers and is shown in Fig. 9. The comparison with Damianides and Westwater (1988) is shown in Fig. 9(a) while that of Yang and Shieh (2001) is shown in Fig. 9(b). The transitional regime represented as slug-annular regime in the figure was shown by Damianides and Westwater (1988) as Pseudo slug flow. The wavy stratified flow is not observed in the present experiments. These were however shown by Damianides and Westwater (1988) as well as Yang and Shieh (2001). The present results are found to be in agreement with the flow pattern map of Damianides and Westwater (1988).The slug to slug-annular boundary shifts towards higher gas velocity in the flow pattern map of Yang and Shieh (2001).

Coleman and Garimella (1999) proposed the flow regime maps for $2.6 \mathrm{~mm}$ and $5.5 \mathrm{~mm}$ tube for the same working fluids as shown in Fig. 9(c). The present flow pattern map for $2.5 \mathrm{~mm}$ tube is compared with their results. Plug, slug and intermittent regime in the flow pattern map by Coleman and Garimella are here termed as slug flow regime and wavy-annular regime is termed as slug-annular flow. The dispersed regime is defined as churn regime in the present flow regime map. The wavy-stratified regime for $2.6 \mathrm{~mm}$ and stratified regime for $5.5 \mathrm{~mm}$ tube are not observed in the present study and hence are not shown on the map. Bubbly and Dispersed flow (Churn flow) are found to be over predicted while for other regimes the predictions are found in agreement with the present data.

The experimentally obtained dataset is also compared with the proposed empirical model for $2.5 \mathrm{~mm}$ diameter minichannel and is shown in Fig. 9(d). Here, slug and slug-annular flow patterns are named as intermittent flow while bubbly, slug-bubbly and churn flow patterns are shown as dispersed flow. Stratified flow is not observed but can be predicted based on the empirical model as shown in Fig. 9(d). The intermittent-dispersed and intermittent-annular transition boundaries are correctly predicted. Hence, the developed model predictions are found to be in agreement with the experimental dataset.

\subsection{Comparison with Available Transition Criteria}

Figure 10 shows the comparison of the present and proposed data with theoretically developed flow pattern maps of Taitel and Dukler (1976) as well as Barnea et al. (1983). Mandhane et al. (1974) conducted experiments for conventional channel of $25 \mathrm{~mm}$ diameter and the observed transition lines as shown in Fig. 10(b). It is observed that the data obtained by Mandhane et al. (1974) for conventional channel are in good agreement with the theoretical model of Taitel and Dukler. This demonstrates the prediction capability of the Taitel and Dukler model for macroscale channels.

For micro-scale channels, based on the Fig. 10(a), the prediction of Taitel and Dukler for stratified flow to 


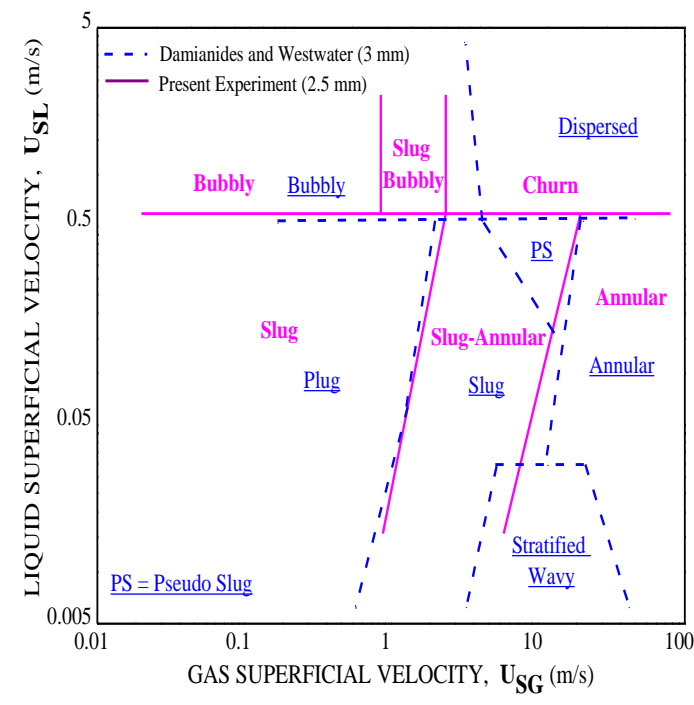

(a) Damianides and Westwater (1988)

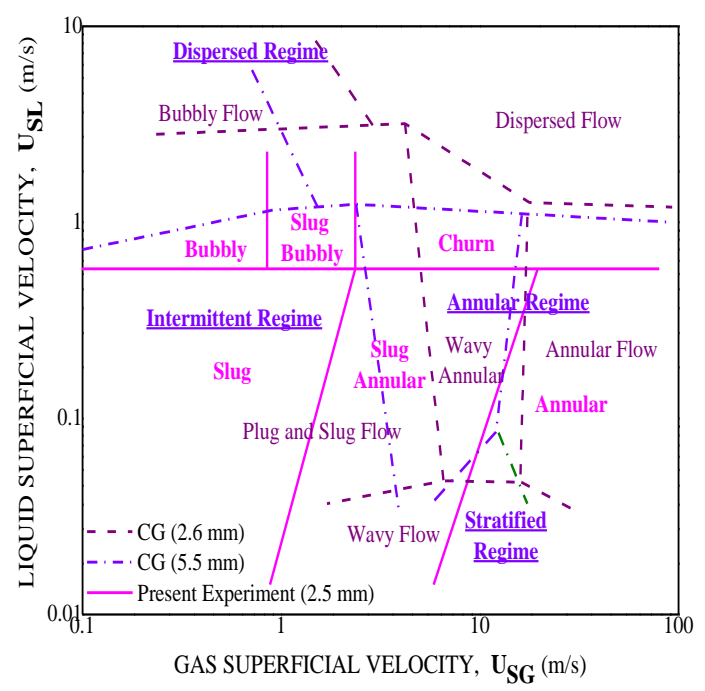

(c) Coleman and Garimella (CG) (1999)

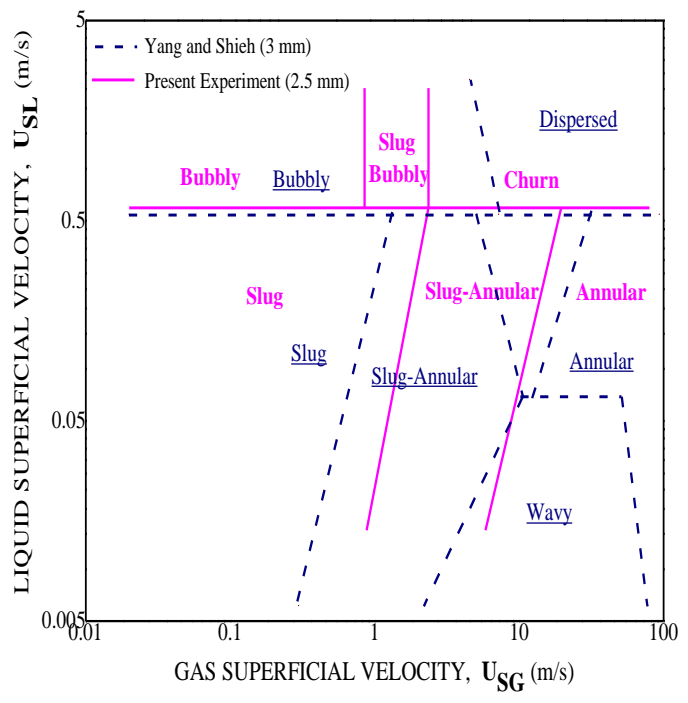

(b) Yang and Shieh (2001)

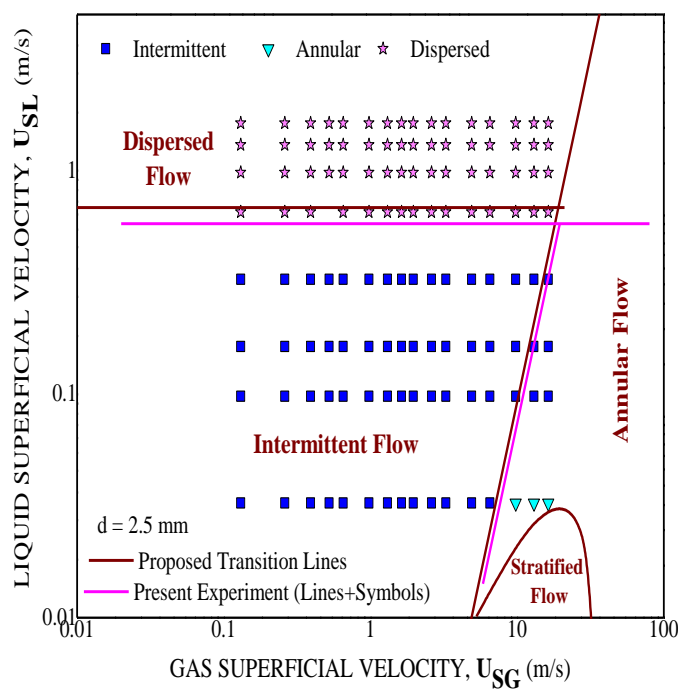

(d) Proposed Empirical Model

Fig. 9. Comparison of present flow map with previous flow pattern maps and proposed empirical model

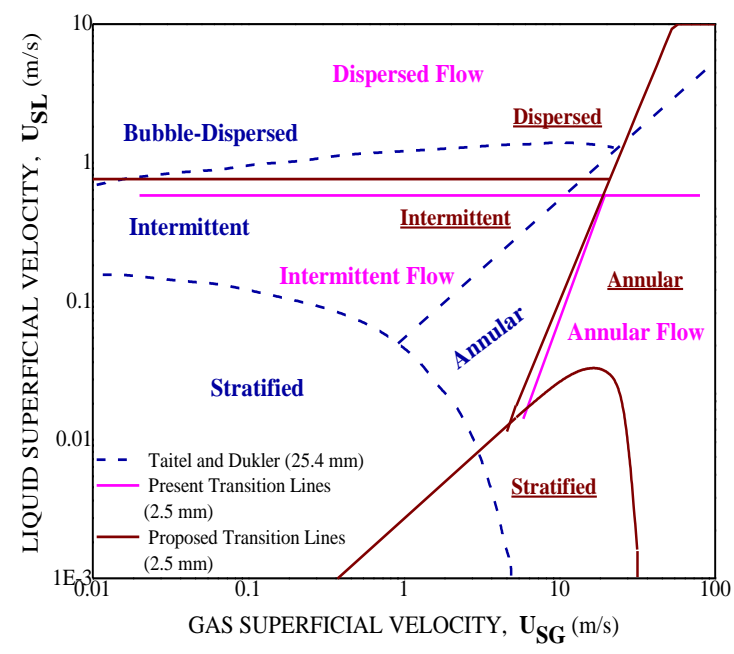

(a) Taitel and Dukler (1976) prediction

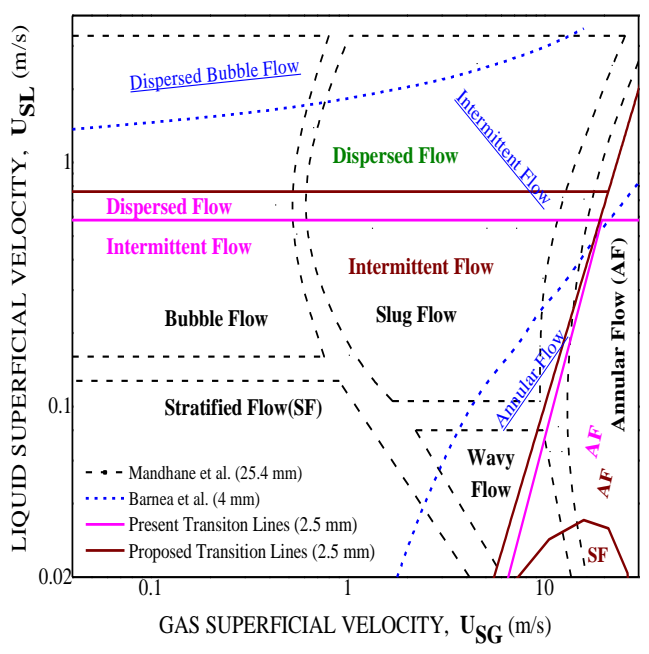

(b) Mandhane et al. (1974) and Barnea et al. (1983)

Fig. 10. Comparison of the proposed empirical model with transition criteria reported in literature 
intermittent flow is not found to be in line with the present and proposed results while intermittentdispersed transition boundary is observed to shift to higher value of water velocity. Taitel and Dukler also suggested that liquid level in the stratified equilibrium flow will only decide the development of intermittent or annular flow. According to their prediction, intermittent flow will develop when the equilibrium liquid level $\left(h_{L}\right)$ in the tube of internal diameter $\left(d_{i}\right)$ is above the tube centerline. Annular or annular-dispersed flow will develop when the ratio is $\left(h_{L} / d_{i}\right)<0.5$. This description is not observed to be true for the present work. The present observations depict that the development of transition boundary from intermittent to annular regime depends mostly on air velocity unlike water velocity as was predicted by the model of Taitel and Dukler. The present experimental results and proposed empirical model are found to be in accordance with the predictions by Barnea et al. (1983).

\section{CONCluSion}

A broad data base from experimental studies in literature for air-water two-phase flow in horizontal circular micro-scale channel of different diameter (1 to $5 \mathrm{~mm}$ ) is presented. A considerable scatter is observed for the flow regime transition boundaries presented by different researchers. This is because of the subjectivity in the flow regime characterization and different terminology used by the authors.

In the present study, for simplicity, four regimes namely intermittent, stratified, dispersed and annular are considered. Based on this flow regime classification, an empirical model is developed and flow regime maps are proposed for minichannel diameters ranging between 2 to $5 \mathrm{~mm}$. Systematic experiments are conducted and flow pattern map is developed for $2.5 \mathrm{~mm}$ diameter pipe. The proposed empirical model for flow pattern transition lines are compared with the work of Mandhane et al. (1974), Taitel and Dukler (1976), Barnea et al. (1983), Damianides and Westwater (1988), Coleman and Garimella (1999), Yang and Shieh (2001), Venkatesan et al. (2010). It is concluded that the proposed empirical model agrees well with experimentally developed flow regime maps of various researchers. However, the theoretical model proposed by Taitel and Dukler (1976) is found to have poor predictability for micro-scale channel while the prediction model of Barnea et al. (1983) is observed to be in reasonable good agreement with experiments. The transition line between stratified and other flow regimes is not predicted well by the proposed model. This is because of the requirement of a broad database of wetting characteristic in order to investigate the effect of contact angle on the transition from stratified to other flow.

\section{ACKNOWLEDGEMENTS}

The authors would like to acknowledge the authorities of the Sardar Vallabhbhai National Institute of Technology, Surat for providing financial support for the development of Advanced Fluid Dynamics Lab where this minichannel based experiments are conducted.

\section{REFERENCES}

Abiev, R. Sh. and I. V. Lavretsov (2012).Intensification of mass transfer from liquid to capillary wall by Taylor vortices in minichannels, bubble velocity and pressure drop. Chemical Engineering Science, 74, 59-68.

Akbar, M. K., D. A. Plummer and S. M. Ghiaasiaan (2003).On gas-liquid two-phase flow regimes in microchannels .Int. J. Multiphase Flow, 29, 855865 .

Barajas, A. M., and R. L. Panton (1993).The effects of contact angle on two-phase flow in capillary tubes. Int. J. Multiphase Flow, 19, 337-346.

Barnea, D., Y. Luninski, and Y. Taitel(1983).Flow Pattern in Horizontal and Vertical Two Phase Flow in Small Diameters Pipes.Can. J. Chem. Eng. 61(5), 617-620.

Bedram A. and A. Moosavi (2013).Breakup of Droplets in Micro and Nanofluidic T-Junctions. Journal of Applied Fluid Mechanics, 61, 81-86.

Chen, W. L., M. C. Twu and C. Pan (2002).Gas-liquid two-phase flow in micro-channels. Int. $J$. Multiphase Flow, 28, 1235-1247.

Cheng, L., R. Gherhardt and J. R. Thome (2008).Twophase flow patterns and flow pattern maps: Fundamentals and Applications. Applied Mechanics Reviews, 61, 050802-1-28.

Chung, P.M.Y. and M. Kawaji (2004).The effect of channel diameter on adiabatic two-phase flow characteristics in microchannels. Int. J. Multiphase Flow, 30, 735-761.

Coleman, J.W. and S. Garimella (1999). Characterization of two-phase flow patterns in small diameter round and rectangular tubes. Int. J. Heat Mass Trans, 42, 2869-2881.

Damianides, C. and J. W. Westwater (1988). Two Phase Flow Patterns in a Compact Heat Exchanger and in Small Tubes. Proceedings of Second U.K. National Conference on Heat Transfer, II, Glasgow, September 14-16, 1988, Mechanical Engineering Publications, London, 1257-1268.

Fukano, T. and A. Kariyasaki (1993). Characteristics of gas-liquid two-phase flow in a capillary. Nuclear Engineering Design, 141, 59-68.

Hassan, I., M. Vaillancourt and K. Pehlivan (2005). Two-phase flow regime transitions in microchannels: a comparative experimental study. Microscale Therm. Engg., 9, 165-182.

Kandlikar, S. G. and W. J. Grande (2003). Evolution of microchannel flow passages - Thermo hydraulic 
performance and fabrication technology. Heat TransferEngg.,24(1), 3-17.

Kline, S. J. and K. N. Mc.Clintock (1953). The Descriptions of Uncertainties in Single Sample Experiments. Mechanical Engineering, 75.

Leung, S. Y. Sh., R. Gupta, D. F. Fletcher and B. S. Haynes (2012).Gravitational effect on Taylor flow in horizontal microchannels. Chemical Engineering Science69, 553-564.

Mandhane, J. M., G. A. Gregory and K. Aziz (1974). A Flow Pattern Map for Gas Liquid Flow in Horizontal Pipes. Int. J. Multiphase Flow, 1, 537553.

Mishima, K. and T. Hibiki (1996). Some characteristics of air-water two-phase flow in small diameter vertical tubes. Int. J. Multiphase Flow, 22, 703-712.

Mishima, K., T. Hibiki and H. Nishihara (1993). Some characteristics of air-water two-phase flow in narrow rectangular ducts. Int. J. Multiphase Flow, 19, 115-124.

Naik, R., V. Varadarajan, G. Pundarika and K. R. Narasimha (2013). Experimental investigation and Performance Evaluation of a Closed Loop Pulsating Heat Pipe. Journal of Applied Fluid Mechanics, 6(2), 267-275.

Pehlivan, K., I. Hassan and M. Vaillan court (2006). Experimental Study on Two Phase Flow and Pressure Drop in Millimeter-Size Channels. Appl. Therm. Eng., 26, 1506-1514.

Pohorecki, R., P. Sobieszuk, K. Kula, W. Moniuk, M. Zielinski, P. Cyganski and P. Gawinski (2008). Hydrodynamic regimes of gas-liquid flow in a micro- reactor channel. Chemical Engineering Journal, 135, S185-S190.

Saisorn, S. and S. Wongwises (2008). Flow pattern, void fraction and pressure drop of two- phase airwater flow in a horizontal circular micro-channel. Exp. Therm. Fluid Sci., 32, 748-760.

Saisorn, S. and S. Wongwises (2009). An experimental investigation of two-phase air-water flow through a horizontal circular micro-channel. Experimental Thermal and Fluid Science, 33, 306-315.

Saisorn, S. and S. Wongwises (2010). The effects of channel diameter on flow pattern void fraction and pressure drop of two-phase air-water flow in circular micro-channels. Experimental Thermal and Fluid Science, 34, 454-462.

Shao, N., A. Gavriilidis and P. Angeli (2009). Flow regimes for adiabatic gas-liquid flow in microchannels. International Journal of Multiphase Flow, 64, 2749-2761.

Taitel, Y. and A. E. Dukler (1976). A Model for Predicting Flow Regime Transitions in Horizontal and Near Horizontal Gas Liquid Flow. AIChE J, 22(1), 47-55.

Taitel, Y., D. Barnea and A. E. Dukler (1980). Modeling flow pattern transitions for steady upward gas-liquid flow in vertical tubes. AIChE J., 26, 345354.

Triplett, K. A., S.M. Ghiaasiaan, S.I. Abdel-Khalik and D.L. Sadowski (1999). Gas-liquid two-phase flow in microchannels Part I: Two-phase flow patterns. Int. J. Multiphase Flow, 25, 377-394.

Vaillancourt, M. P., I. G. Hassan and K. K. Pehlivan (2004). Two-phase flow regime transitions in microchannels. Proceeding of $5^{\text {th }}$ International Conference on Multiphase Flow, ICMF'04, Yokohama, Japan.

Venkatesan, M., S. K. Das and A. R. Balakrishnan (2011). Effect of diameter on two-phase pressure drop in narrow tubes. Experimental Thermal and Fluid Science, 35, 531-541.

Yang, C.Y. and C. C. Shieh (2001). Flow pattern of airwater and two-phase R-134a in small circular tubes. Int. J. Multiphase Flow, 27, 1163-1177.

Zhang, L., T. B. Xiaotao, D. P. Wilkinson, R. Anderson, J. Stumper and H. Wang (2011). Gasliquid two-phase flow behaviour in minichannels bounded with a permeable wall. Chemical Engineering Science, 66, 3377-3385.

Zhao, T. S. and Q. C. Bi (2001). Co-current air-water two-phase flow patterns in vertical triangular microchannels. Int. J. Multiphase Flow, 27, 765782.

Zobeiri, A. (2006). Flow pattern characterization for air-water flow by high speed visualization, optical measurement and dynamic pressure signal, Master thesis, École Polytechnique Fédérale de Lausanne (EPFL), Lausanne, Switzerland. 